\title{
LURKING DANGERS IN DEEP NECK ABSCESS RETROSPECTIVE STUDY
}

\section{S. Dhanalakshmi ${ }^{1}$}

\section{HOW TO CITE THIS ARTICLE:}

S. Dhanalakshmi "Lurking Dangers in Deep Neck Abscess Retrospective Study". Journal of Evolution of Medical and Dental Sciences 2015; Vol. 4, Issue 46, June 08; Page: 7977-7985, DOI: 10. 14260/jemds/2015/1160

ABSTRACT: AIM: A retrospective study was conducted to identify the predisposing risk factors related with outcome in deep neck infections. SETTING: The study was carried out in the Department of ENT, Coimbatore Medical College Hospital, Coimbatore. This is a tertiary referral center hospital. MATERIALS \& METHODS: The subjects included 85 patients who had inpatient treatment at Coimbatore Medical College Hospital from January 2004 to December 2014. The parameters studied were age, sex, co-morbidity and complications with management. ${ }^{1-2}$ STATISTICAL ANALYSIS: The data were analyzed using chi square analysis and logistic regression analysis. ${ }^{3}$ RESULTS: The case sheets of 85 patients were analyzed which included 67 men and 18 women. Among these, $83 \%$ had co-morbidity and $20 \%$ had dental infection. Most common space involved was submandibular space infection (Ludwig's angina). Female patients with risk factors developed complications. The therapeutic was success achieved only with empiric antibiotics in all patients without complications. Surgical procedures were lifesaving in patients with complications. ${ }^{4-6}$ CONCLUSION: High risk patients need priority attention which includes early treatment with broad spectrum intravenous (iv) antibiotics with surgical drainage or dental extraction or with both or with or without tracheostomy. Empiric antibiotics are effective with minimal disease.

KEYWORDS: Neck abscess, Deep neck space infection, Cervical necrotising faciitis.

INTRODUCTION: Outcome of deep neck space infections continue to be associated with severe illness and death. Retrospective studies are warranted related to deep neck space infection with etiology, associated co-morbidity, and clinical radiological diagnosis versus microbiology, life threatening complications, treatment and duration of hospital stay. ${ }^{7-10}$ Furthermore, tt is also important for all the otolaryngologists to pay more attention to high risk patients with neck swelling and respiratory difficulty.

METHODS: This retrospective study was conducted in patients with deep neck space infection treated at Coimbatore Medical College Hospital, Coimbatore between January 2004 to December 2014. The total number of patients treated were 85 including 67 men and 18 women with age ranging from 0 to 75 years (mean $30.4 \pm 16.20$ Std. deviation). Out of 85 cases, $78 \%$ were males and $20 \%$ were females. ${ }^{11,12}$

\section{Age Vs Sex Distribution:}

\begin{tabular}{|c|c|c|c|c|}
\hline Age & Male & Female & Male \% & Female\% \\
\hline 0 to 20 & 22 & 8 & 26 & 9 \\
\hline 21 to 40 & 26 & 6 & 31 & 7 \\
\hline 41 to 60 & 14 & 3 & 16 & 4 \\
\hline 61 to 80 & 5 & 1 & 5 & 1 \\
\hline \multicolumn{5}{|c|}{ Table 1: Age/Sex distribution } \\
\hline
\end{tabular}




\section{Age Vs Gender Graph:}

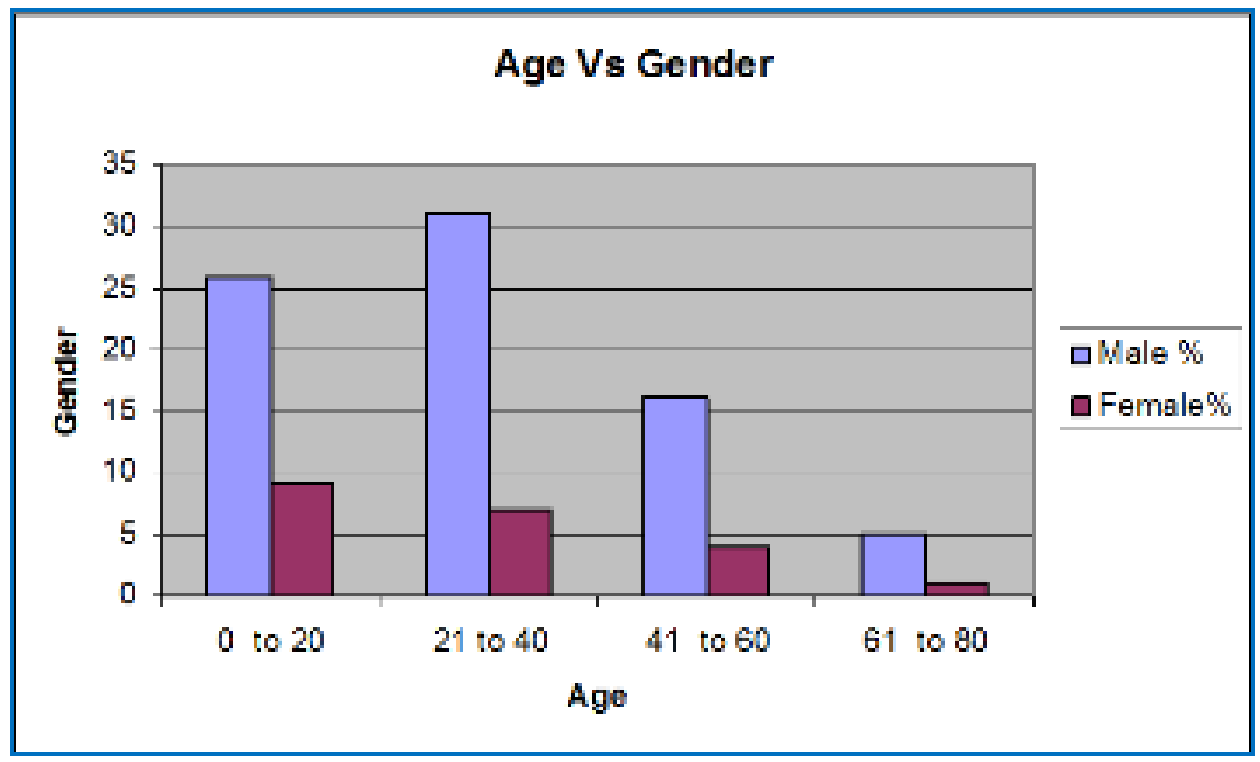

Figure 1: Age Vs Gender Graph

The occurrence of the neck abscess is more common in male between the ages of 0 to 40 years $(73 \%)$.

Income Group: When compared between the entire groups to those in the available literature, people belonging to low social economic group were more prone for infection.

Diagnosis: Patients presented with sudden onset of swelling of lower jaw, check \& neck /trismus/fever/cough/hoarse voice/dysphagia/stridor with shorter duration were included. With detailed history, clinical ENT examination, radiological investigation, therapeutic needling and transcervical drainage, the following diagnosis were made such as parotid abscess, peritonsillar abscess, Ludwig's angina, parapharyngeal, retropharyngeal, neck space abscess, necrotizing cervical fasciitis and mediastinitis. ${ }^{2,5,13}$

\section{Diagnosis Vs Gender:}

\begin{tabular}{|c|c|c|c|c|}
\hline Diagnosis & Male & $\mathbf{\%}$ & Female & \% \\
\hline Ludwig's angina & 35 & $52 \%$ & 4 & $22 \%$ \\
\hline Peritonsillar abscess & 8 & $12 \%$ & 0 & \\
\hline Parotid abscess & 11 & $16 \%$ & 6 & $33 \%$ \\
\hline Parapharyngeal abscess & 3 & $4 \%$ & 7 & $39 \%$ \\
\hline Retro Pharyngeal abscess & 6 & $9 \%$ & 1 & $6 \%$ \\
\hline Necrotizing fasciitis & 4 & $6 \%$ & 0 & \\
\hline \multicolumn{4}{|c|}{ Table 2: Diagnosis Vs Gender } \\
\hline
\end{tabular}




\section{ORIGINAL ARTICLE}

\section{Diagnosis Vs Gender:}

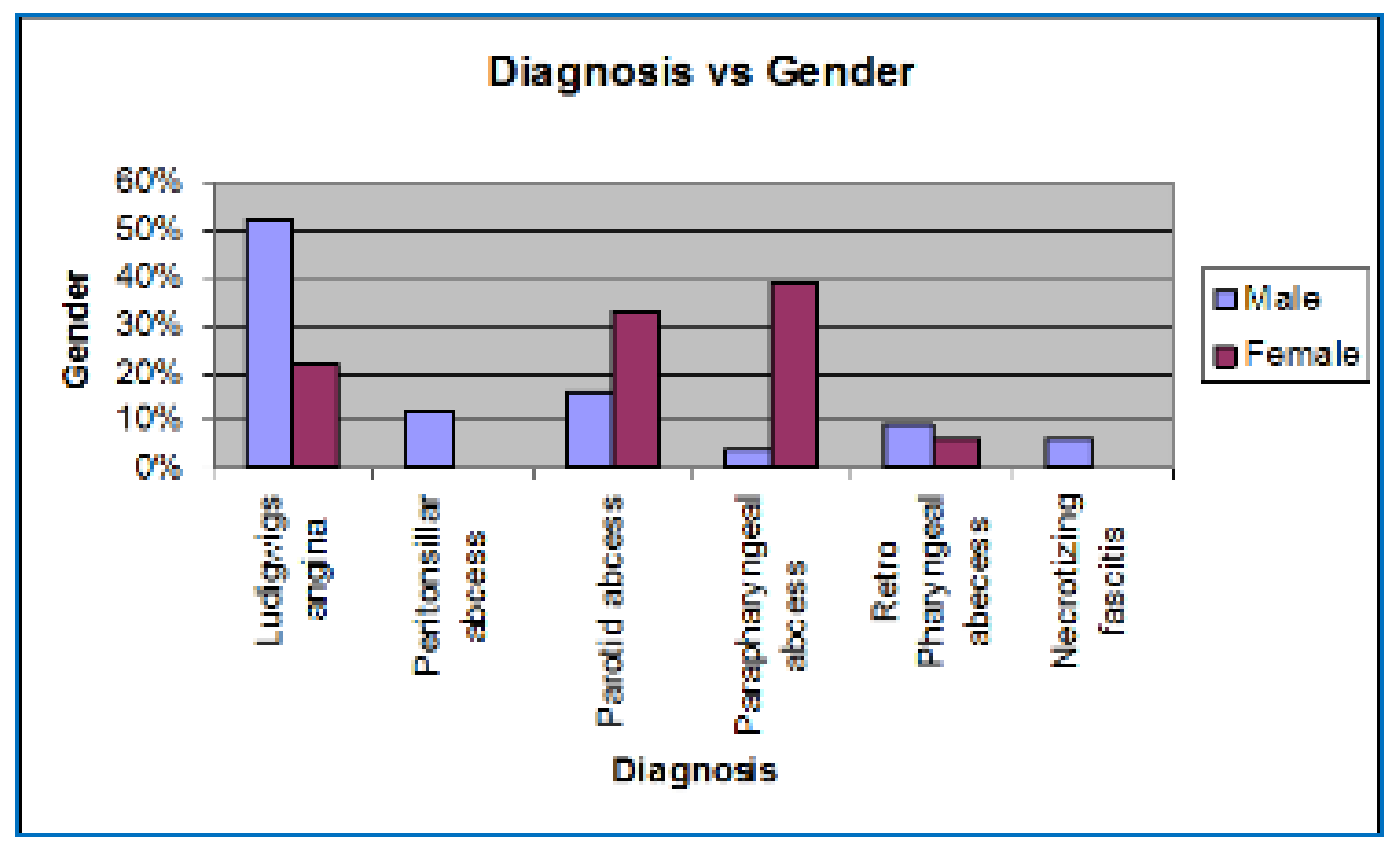

Figure 2: Diagnosis Vs Gender

Among 18 female patients 7 had para pharyngeal abscess (39\%) which is significantly associated with sex $\&$ diagnosis. The result of CHI - Square analysis $(\mathrm{x} 2=22.52)$ showed $\mathrm{P}<0.01$.

\section{CT Scan of Ludwig's Angina:}

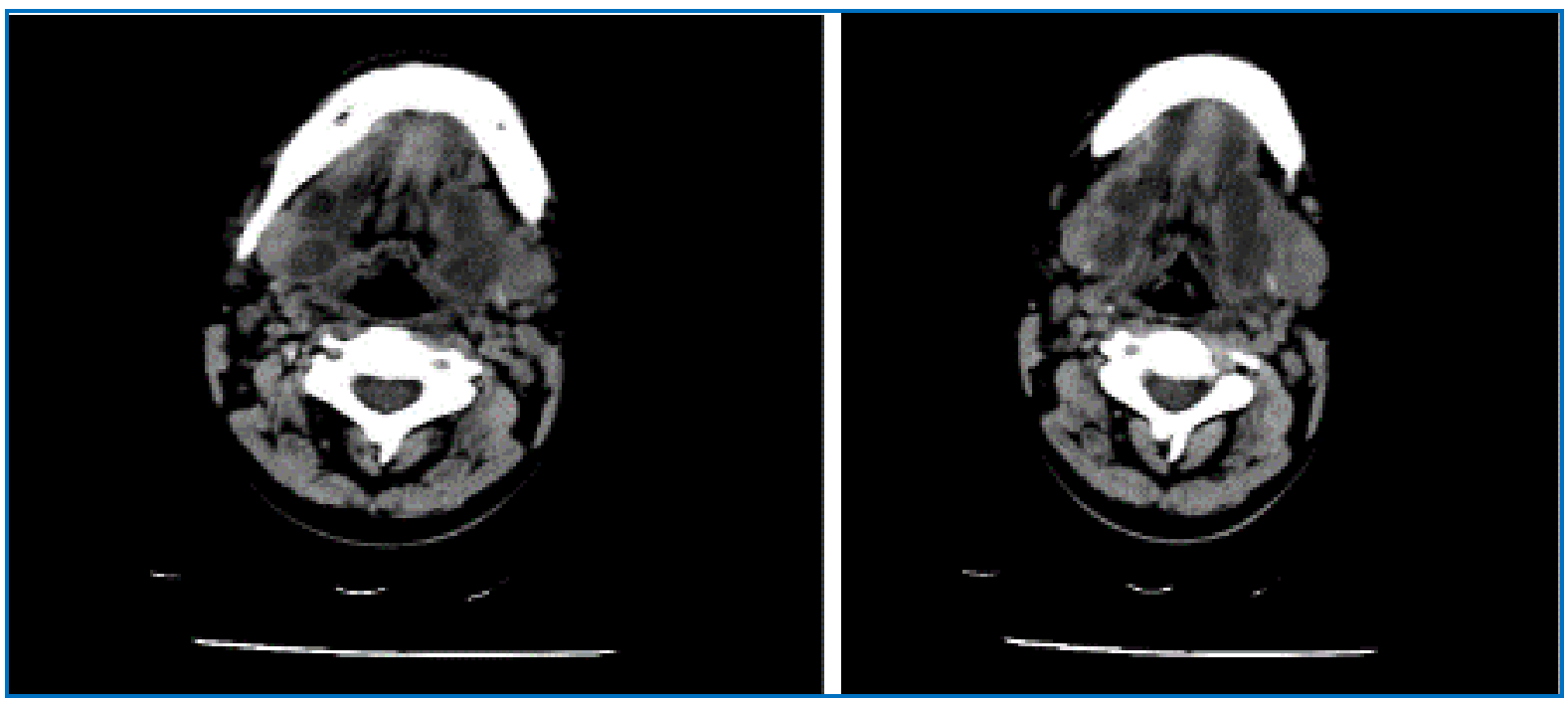

Figure 3: CT Scan of Ludwig's Angina 


\section{ORIGINAL ARTICLE}

\section{Neck Space Abscess with Mediastinal Extension:}

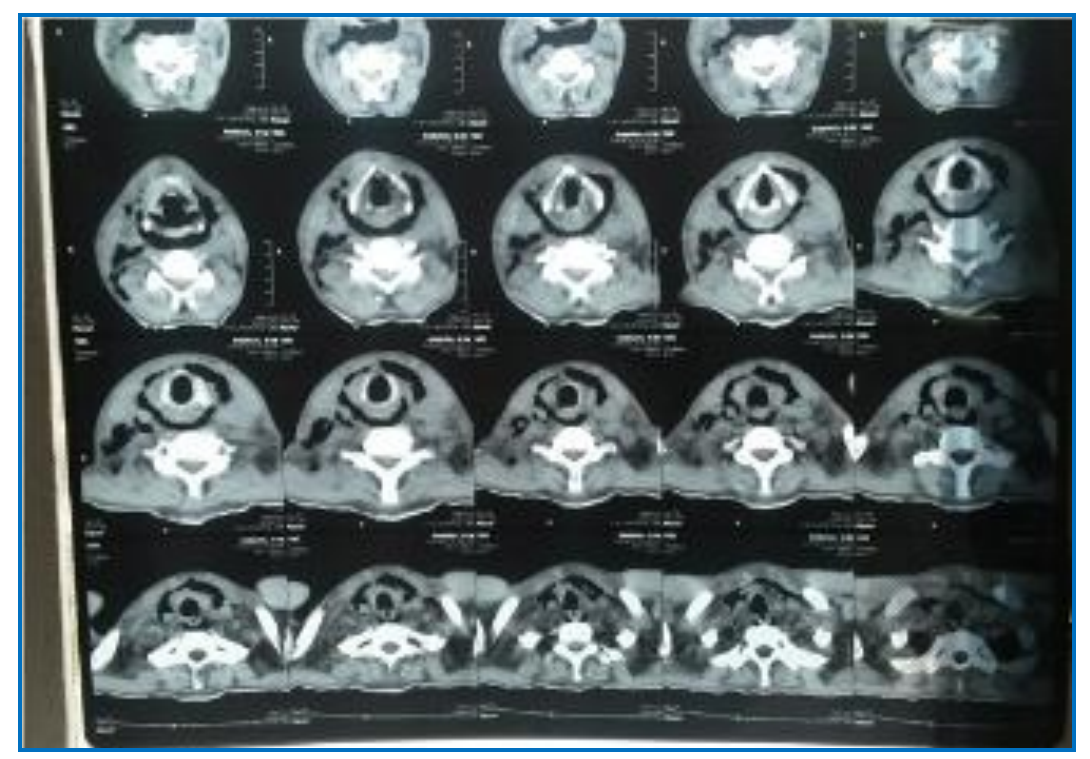

Figure 4: Neck Space Abscess with Mediastinal Extension

\section{Comorbidity \& Complications:}

\begin{tabular}{|c|c|c|c|c|}
\hline Co Morbidity & Male & $\%$ & Female & $\%$ \\
\hline Diabetes & 18 & $27 \%$ & 4 & $22 \%$ \\
\hline Hypertension & 9 & $13 \%$ & 2 & $11 \%$ \\
\hline Dental sepsis & 7 & $10 \%$ & 10 & $56 \%$ \\
\hline Stridor & 2 & $3 \%$ & 0 & 0 \\
\hline Mediastnitis & 2 & $3 \%$ & 0 & 0 \\
\hline Death & 8 & $12 \%$ & 1 & $6 \%$ \\
\hline
\end{tabular}

In CHI-Square analysis with morbidity and mortality the $\mathrm{P}$ value reached statistically significant $(\mathrm{P}<0.05)$. Incidence of T2DM $22 \%$ and dental sepsis $56 \%$ were more in female patients.

Microbiology: Deep neck infection is frequently polymicrobial and often caused by oral bacteria. Aspiration and pus culture were sent for 40 patients. No growth was reported in 32 patients. Staphylococcus aureus was found in 2 patients which was not commonly found in the mouth.

\section{Treatment details:}

\begin{tabular}{|c|c|c|c|c|}
\hline Treatment & Male & $\mathbf{~ \% ~}$ & Female & $\mathbf{\%}$ \\
\hline IV antibiotics only & 45 & $67 \%$ & 5 & $28 \%$ \\
\hline Antibiotic With I\&D & 13 & $19 \%$ & 5 & $28 \%$ \\
\hline Antibiotic with Dental extraction & 5 & $7 \%$ & 7 & $39 \%$ \\
\hline Antibiotic with Tracheostomy & 4 & $6 \%$ & 1 & $6 \%$ \\
\hline Table 4: Treatment Vs Gender
\end{tabular}




\section{ORIGINAL ARTICLE}

\section{I \& D done with Ludwig's Angina:}

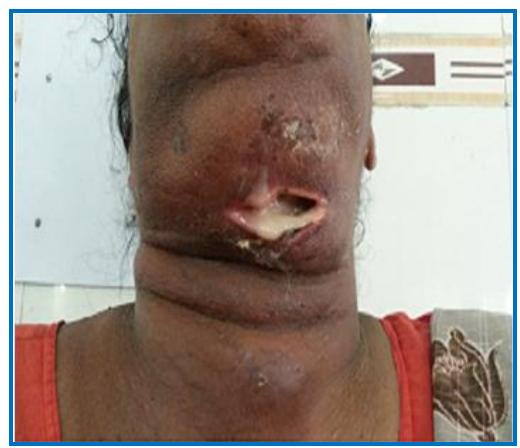

\section{Figure 5: I \& D done with Ludwig's Angina}

Tracheostomy Done:

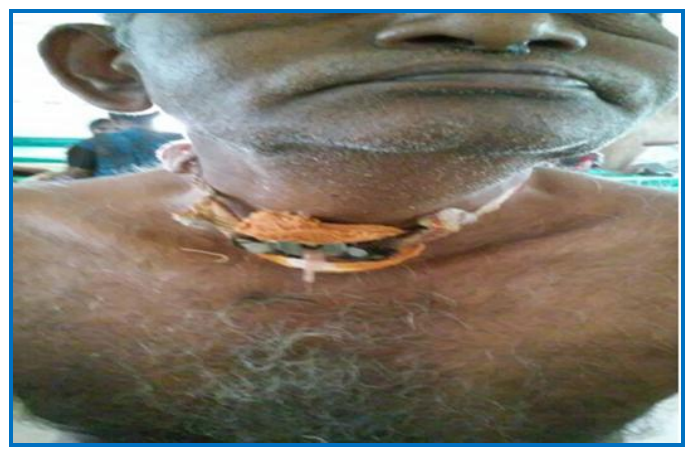

Figure 6: Tracheostomy Done

Treatment Vs Gender:

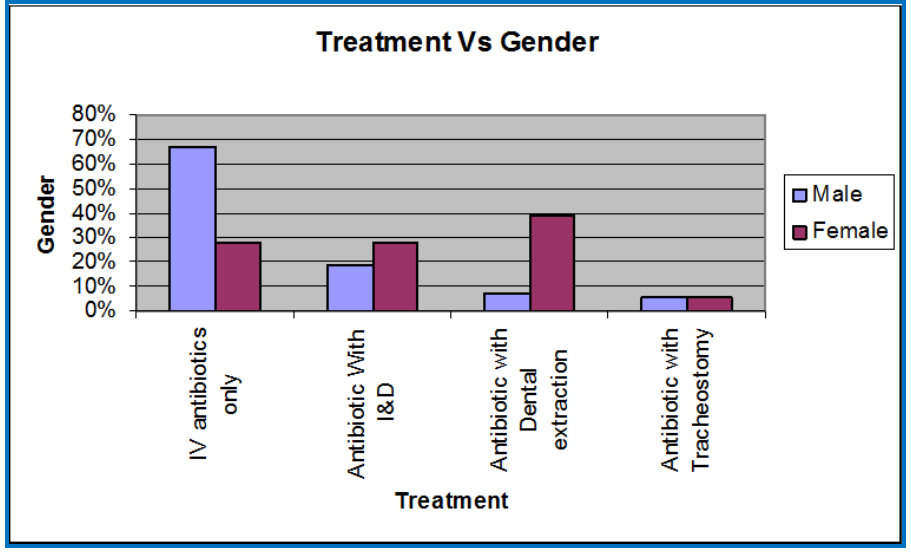

Figure 7: Treatment Vs Gender

The $\mathrm{x} 2$ test $(\mathrm{P}<0.01)$ shows that treatment modality is significantly associated with gender. Management with antibiotic and procedures are more beneficial than management with antibiotics alone.(14) 


\begin{tabular}{|c|c|c|c|c|}
\hline Days & Male & Female & Total & $\mathbf{\%}$ \\
\hline 0 to 7 & 40 & 12 & 52 & 61 \\
\hline 8 to 14 & 24 & 6 & 30 & 35 \\
\hline 15 to 21 & 2 & 0 & 2 & 2 \\
\hline 22 to 30 & 1 & 0 & 1 & 1 \\
\hline \multicolumn{5}{|c}{ Table 5: Hospital stay } \\
\hline
\end{tabular}

Hospital stay was prolonged with co morbidity and in tracheostomised patients.

\section{DISCUSSION:}

Applied Anatomy: The layers of cervical fascia create potential spaces which results in dangerous life threatening infection. Buccal, canine, mastigator, parotid spaces are commonly involved in face. In the neck, infection spreads from peritonsillar, submandibular, sublingual, lateral pharyngeal and anterior visceral space extending to retropharyngeal, prevertebral and carotid sheath spaces.

Outcome of deep neck space infections continue to be associated with severe illness and death. Empiric antibiotic treatment and aspiration for drainage is still the main stay of the management which has improved the outcome of deep neck space infection. If infection is odontogenic, dental extraction is beneficial. Ludwig's angina required intubation or emergency tracheostomy which is lifesaving. Trans cervical drainage with pus or tissue specimen for culture and pathologic evaluation with additional wound debridement prevent recuperative complications such as septic emboli, septic shock and pulmonary aspiration.(10,15-19)

Use of antibiotics in healthy patients for effective treatment (5 TO 7 DAYS) are Ampicillin sulbactam 1.5 to $3 \mathrm{~g}$ iv every 6 hours or Cefoxitin 1 to $2 \mathrm{~g}$ iv every 6 hours alternative for penicillin allergic patients Clindamycin 600 to $900 \mathrm{mg}$ iv every 8 hours or Ceftriaxone 1 to $2 \mathrm{~g}$ iv every 12 hours. In compromised or hospitalized patients or Pseudomonas aeruginosa suspected (Duration 3 WEEKS) Piperacillin-tazobactam 3 to 0.375 g I every 4 to 6 hours, or Clindamycin 600 to $900 \mathrm{mg}$ iv every 12 hours or plus Ceftazidime 1 to 2 every 12 hours for necrotising fasciitis Ceftriaxone 2g iv every 8 hours plus Clindamycin $900 \mathrm{mg}$ iv every 8 hours or plus Metronidazole 500mg iv every 6 hours for 2 weeks are mandatory. ${ }^{(17)}$

RESULTS: The case sheets of 85 patients were analyzed among which 67 (78\%) were men and 18 $(22 \%)$ were women. Sixty two (73\%) of the patients were lesser than 40 years of age. There were 70 (83\%) patients who had associated with systemic diseases, of those having diabetic mellitus is 22 (26\%), Dental infection was the common cause of deep neck infection 17 (20\%). Ludwig's angina (sub mandibular and sub lingual spaces) was the most commonly involved space (46\%). 18 (21\%) patients underwent surgical drainage. $5(6 \%)$ patients developed lethal complication who received tracheostomy. Those patients with systemic complications or who received tracheostomy had longer hospital stay with mean 7. 47 days. There were 9 deaths (Mortality rate -11\%). 


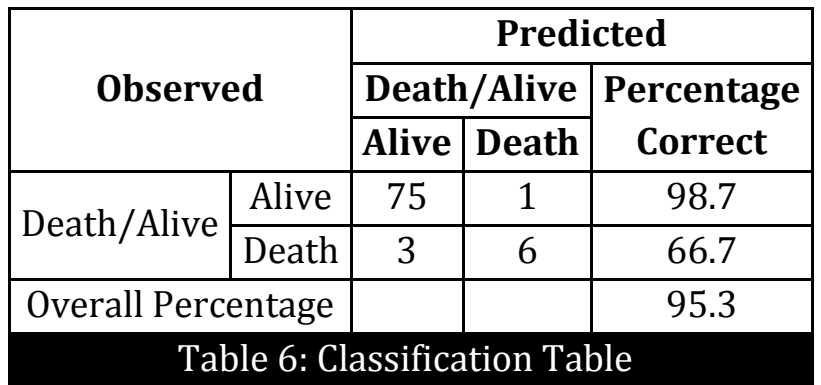

Classification table shows that the regression model has predicted $95.3 \%$ of cases are correctly in the respective death or alive group.

\begin{tabular}{|c|c|c|c|c|}
\hline & $\bar{B}$ & S.E. & P-value & Odds Ratio \\
\hline Gender & .245 & 1.830 & $\mathrm{P}>0.05$ & 1.278 \\
\hline Age & -.008 & .060 & $\mathrm{P}>0.05$ & .992 \\
\hline Onset days & .345 & .726 & $\mathrm{P}>0.05$ & 1.413 \\
\hline Hospital stay (days) & .065 & .138 & $\mathrm{P}>0.05$ & 1.068 \\
\hline Parapharyngeal abscess & 1.227 & 1.927 & $\mathrm{P}>0.05$ & 3.411 \\
\hline Necrotising fasciitis & 3.156 & 1.565 & $\mathrm{P}<0.05$ & 23.478 \\
\hline Retropharyngeal abscess & 3.408 & 1.632 & $\mathrm{P}<0.05$ & 30.200 \\
\hline Diabetics & 2.647 & 1.538 & $\mathrm{P}<0.10$ & 14.111 \\
\hline SHT & 2.180 & 1.747 & $\mathrm{P}>0.05$ & 8.846 \\
\hline (Constant) & -6.465 & 2.415 & & \\
\hline
\end{tabular}

Logistic regression analysis was performed to predict the mortality of neck abscess with the parameters such as gender, age, onset days, hospital stay, parapharyngeal abscess, necrotizing fasciitis, diabetes and systemic hypertension. The results show that necrotizing fasciitis and parapharyngeal abscess and diabetes were found to be significant predictors of mortality. The patients with necrotizing fasciitis are 23.47 times more fatal than those who do not have. Similarly retropharyngeal abscess is 30 times more fatal and with DM is 14 times more fatal. In case of SHT even though it is not a significant predictor, those with SHT are 8.8 times more prone for complications.

DISCUSSION: The layers of cervical fascia create potential spaces resulting in dangerous life threatening infections. In face buccal, canine, mastigator, parotid spaces are involved. In the neck, infection spreads from peritonsillar, submandibular, sublingual, lateral pharyngeal and anterior visceral space extending to retropharyngeal prevertebral and carotid sheath spaces.

Empiric antibiotic treatment and aspiration for drainage is still the main stay of the management which has improved the outcome of deep neck space infection. If infection is odontogenic, dental extraction is beneficial. Ludwig's angina required intubation or emergency tracheostomy which is lifesaving. Transcervical drainage with pus or tissue specimen for culture and 
pathologic evaluation with additional wound debridement prevent recuperative complications such as septic emboli, septic shock and pulmonary aspiration. ${ }^{10,15-19}$

Use of antibiotics in healthy patients for effective treatment (5 to 7 days) are Ampicillin sulbactam 1.5 to $3 \mathrm{~g}$ iv every 6 hours or Cefoxitin 1 to $2 \mathrm{~g}$ iv every 6 hours alternative for penicillin allergic patients Clindamycin 600 to $900 \mathrm{mg}$ iv every 8 hours or Ceftriaxone 1 to $2 \mathrm{~g}$ iv every 12 hours. In compromised or hospitalized patients or pseudomonas aeruginosa suspected (3 weeks) Piperacillin - tazobactam 3 to 0.375 g I every 4 to 6 hours, or Clindamycin 600 to $900 \mathrm{mg}$ iv every 12 hours or plus Ceftazidime 1 to 2 every 12 hours for necrotising fasciitis Ceftriaxone 2 g iv every 8 hours plus Clindamycin $900 \mathrm{mg}$ iv every 8 hours or plus Metronidazole $500 \mathrm{mg}$ iv every 6 hours for 2 weeks. ${ }^{17}$

CONCLUSION: The present study suggests that treatment of deep neck infection in a higher risk group (Older age with diabetics, with dental sepsis) needs priority attention to prevent complications and even the possibility of death. Early surgical drainage and tracheostomy proved to be the main stay with empiric antibiotic therapy.

ACKNOWLEDGEMENT: The author thanks Dr. Edwin Joe M. D. (Forensic), B. L, Dean, Coimbatore Medical College Hospital for his guidance and comments regarding the research.

\section{REFERENCES:}

1. Parhiscar A, Har-El G: Deep Neck abscess: a retrospective review of 210 cases, Ann otorhino laryngol 110: 1051, 2001.

2. Tom MB, Rice DH: Presentation and management of neck abscess: a retrospective analysis, Laryngoscope 98: 877, 1988.

3. Ungkanont $\mathrm{K}$ and others: Head and neck space infections in infants and children, Otolaryngology Head Neck Surg 112: 375, 1995.

4. Nagy $M$ and others: Deep neck infections in children: a new approach to diagnosis and treatment, Laryngoscope 107: 1627, 1997.

5. Yeow KM, Liao CT Hao SP; US guided needle aspiration and catheter drainage as an alternative to open surgical drainage for uniloculated neck abscesses, J Vasc Interv Radiol 12: 589, 2001.

6. Rapport $Y$ and others; Cervical necrotizing fascitis of odotogenic origin, oral surg oral med oral Pathol 72: 15, 1991.

7. Mathieu D and others: Cervical necrotizing fasciitis: clinical manifestations and management, Clin Infect Dis 21: 51, 1995.

8. Baker AS, Monotgomery WW: oropharyngeal space infections, Curr Clin Top Infect Dis 8: 227, 1987.

9. Broughton RA: Nonsurgical management of deep neck infections in children, Pediatr Infect Dis J 11: 14, 1992.

10. Chow AW: Life - threatening infections of the head and neck, Clin Infect dis 14: 991, 1992.

11. Dodds B, Manigilia AJ: Peritonsillar and neck abscesses in the pediatric age group, Laryngoscope 90: 1111, 1980.

12. Finch RD, Snider GE, Sprinkle PM: Ludwig's angina, JAMA 243: 1171, 1980.

13. Gidley PW, Ghorayed BY, Stiernberg CW: Contemporaray management of deep neck space infections, Otolaryngol head neck surg 116: 16, 1997. 


\section{ORIGINAL ARTICLE}

14. Mayor GP, Martinez-San Millan J, Martinez-Vidal A: Is Conservative treatment of deep neck space infectious appropriate? Head Neck 23: 126, 2001.

15. Sethi DS, Stanley RE: Deep neck abscesses - changing trends, J laryngol otol 108: 138, 1994.

16. Wheatley MJ and others: Descending necrotizing mediastinitis: transcervical drainage is not enough, Ann Thoroc Surg 49: 780, 1990.

17. Meshel RH, Karlen R: Cervical necrotizing fasciitis, Laryngoscope 104: 795, 1994.

18. Balcerak RJ, Sisto JM, Bosak RC: Cervicofacial necrotizing fasciitis, J Oral Maxillofac Surg 46: 450, 1988.

19. Francisco Vieira, Shawn M Allen, Rose Mary S. Stocks, Jerome W. Thompson: Deep neck infection, volume 41, issue 3, 459: 483, June 2008.

\section{AUTHORS:}

1. S. Dhanalakshmi

\section{PARTICULARS OF CONTRIBUTORS:}

1. Associate Professor, Department of ENT, Coimbatore Medical College, Coimbatore.

FINANCIAL OR OTHER COMPETING INTERESTS: None

\section{NAME ADDRESS EMAIL ID OF THE CORRESPONDING AUTHOR:}

Dr. S. Dhanalakshmi,

Majestic Landmark,

Sivanandha Colony,

Coimbatore-641012.

E-mail: dhanalakshmithara@gmail.com

Date of Submission: 01/05/2015.

Date of Peer Review: 02/05/2015.

Date of Acceptance: 30/05/2015.

Date of Publishing: 06/06/2015. 